\title{
Application of response surface methodology for the optimization of hydro-distillation extraction of Pistacia lentiscus L. essential oil
}

\author{
Taoufik Haloui", Abdellah Farah', Sara Lebrazi ${ }^{3}$, Mouhcine Fadil', Aziz Belrhiti Alaoui' \\ 'Laboratory of Functional Ecology and Environment, Faculty of Sciences and Technology, Sidi Mohamed Ben Abdellah University, BP 2202 - Road Imou- \\ zzer. Fez, Morocco. \\ ${ }^{2}$ Application Organic Chemistry Laboratory, Faculty of Sciences and Technology, Sidi Mohamed Ben Abdellah University, BP 2202 - Road Imouzzer. Fez, \\ Morocco. \\ ${ }^{3}$ Laboratory of Microbial Biotechnology, Faculty of Science and Technology, Sidi Mohamed Ben Abdellah University, P.O.Box 2202. Fez, Morocco.
}

\section{ARTICLE INFO \\ Article history: \\ Received on: 20/03/2017 \\ Accepted on: 21/05/2017 \\ Available online: 28/01/2018}

Key words:

Pistacia lentiscus, essen-

tial oil, hydro-distillation,

composite design, response

surface

\begin{abstract}
The evaluation of the optimum conditions for extraction of Pistacia lentiscus essential oil by hydro-distillation process required a design of experiments (DOE). The selected factors of composite design are the time of hydro-distillation and the ratio of the plant material and water. Response surface methodology was used to evaluate the effects of processing parameters and the extraction yields varied in the range of $0.4-0.58 \%(\mathrm{w} / \mathrm{w})$ under different conditions. This study proved high efficiency of the response surface methodology application to optimize the operational parameters influencing the yield of essential oil extracted by hydro-distillation process of Pistcia lentiscus L. leaves To get a better essential oil yield with the most economic operating parameters.
\end{abstract}

\section{INTRODUCTION}

Pistacia lentiscus L. belongs to the Anacardiaceae family, also called pistachio mastic or mastic tree. The Arabic Name for this herb is Derou or Meska (Hmamouchi, 2001). Originally from the Mediterranean, mastic tree is an evergreen sclerophyllous shrub, it can reach up to $3 \mathrm{~m}$. P. lentiscus grows wild in the forests and scrub of the plains and low mountains (Hmamouchi, 2001). The area of mastic tree embraces the entire Mediterranean basin and grows on all soil types (Bayer, 2009).

The essential oil of mastic has been shown to have antibacterial (Djenane et al., 2011; Haloui et al., 2015a), Antifungal (Duru et al., 2003), Antioxidant (Benhammou et al., 2008) and insecticide effects (Bachrouch et al., 2010). It is also used in cosmetics, perfumery and as a flavoring in food preparations (Daferera et al., 2002).

${ }^{*}$ Corresponding Author

Taoufik Haloui

E-mail:taoufik.haloui@gmail.com
To ensure the profitability of essential oil production of P. lentiscus, research/development strategies should be referred to sustainably optimize these resources. Thus, improving the essential oil yield is a prime necessity; this becomes more accessible through the application of statistical techniques such as design of experiments (DOE), a technique which consists in proposing little experience all by varying all factors simultaneously in order to obtain maximum information (Tinsson, 2010). In this work, we used the DOE technique as the response surface methodology (RSM) that can be considered as the ideal tool which offers the possibility of a modeling study of extraction phenomenon by steam distillation of $P$. lentiscus essential oil.

\section{MATERIAL AND METHODS}

\section{Plant material}

Mature leaves of $P$. lentiscus used for this study are from the province of Taounate in Morocco. Harvested leaves were brewed in order to homogenize the mixture which was placed in 
shade and in open air. The plant material was spread thinly and rotated frequently during drying period of seven-day (Haloui et al., 2015b).

\section{Extraction of the essential oil}

Hydro-distillation is made with the Clevenger type apparatus (Clevenger, 1928). 100g of plant material was extracted in each test. The plant material moisture is determined by stoving at $105^{\circ} \mathrm{C}$ for 4 hours (Zrira et al., 1991) and yields are expressed relative to the dry matter. The essential oil obtained is stored in refrigerator in an opaque glass bottle to block light sensitive at $4^{\circ} \mathrm{C}$.

\section{Chemical analysis of essential oil}

The essential oil was analyzed using Gas chromatography (GC) coupled to mass spectrometry GC/MS (Polaris Q ion trap MS). Hence, analyses were performed on a Hewlett-Packard (HP 6890) gas chromatograph (FID), equipped with a 5\% phenyl methyl silicone HP-5 capillary column $(30 \mathrm{~m} \times 0.25 \mathrm{~mm} \times$ film thickness $0.25 \mu \mathrm{m})$. The temperature was programmed from $50^{\circ} \mathrm{C}$ after 5 min initial hold to $200^{\circ} \mathrm{C}$ at $4^{\circ} \mathrm{C} / \mathrm{min}$. Chromatography carrier gas was N2 (1.8 ml/min), split mode was used (Flow: 72.1 $\mathrm{ml} / \mathrm{min}$, ratio: $1 / 50$ ), temperature of injector and detector was $250^{\circ} \mathrm{C}$, final hold time was $48 \mathrm{~min}$. The machine was led by a computer system type "HP Chem Station" managing its functioning and allowing to follow the evolution of chromatographic analyses. Diluted samples (1/20 in methanol) of $1 \mu \mathrm{l}$ were injected manually.

\section{Response choice}

The studied response in our case is the yield of $P$. lentiscus essential oil:

$$
\mathrm{Y}(\%)=(\mathrm{Weo} / \mathrm{Wd}) \times 100
$$

eq. 1

With:

Y: yield of essential oils (\%); Weo: weight of collected essential oil $(\mathrm{g})$; Wd: weight of dry plant matter $(\mathrm{g})$.

\section{Selection factors}

The choice of factors was taken into account using the results obtained in previous studies concerning the factors affecting the essential oil yield of P. lentiscus extracted by steam distillation (Haloui et al., 2015a; Haloui et al., 2015b; Haloui et al., 2015c) The two studied factors were:

- The time of hydro-distillation operation;

- The ratio of plant material and water.

The choice of factor levels consists of choosing the high and low levels of each factor (Table 1). The factor levels were chosen taking into account the experimental operating limits of the equipment:

- The operation time of hydro-distillation will be varied between 60 and $180 \mathrm{~min}$.

- The ratio between water and plant material in the distillation flask will be varied between 2 and $4 \mathrm{ml} / \mathrm{g}$.
Table 1: Factors and their real and coded levels of the optimization study.

\begin{tabular}{lcccc}
\hline Factors & Variable code & Unit & center & Variation step \\
\hline Time & $\mathrm{X} 1$ & Min & 120 & 60 \\
Ratio (water/plant) & $\mathrm{X} 2$ & $\mathrm{Ml} / \mathrm{g}$ & 3 & 1 \\
\hline
\end{tabular}

Experimental design

The choice of design used in this optimization study has focused on a response surface design of the composite type (design of the second degree).

The use of experimental designs in the analysis and the optimization of the essential oils extraction process was reported by several authors. Some ones have used other types of screening designs such as Plackett-Burman design (Fadil et al., 2016) or complete factorial design (Haj Ammar et al., 2010) and others have performed directly the optimization by using the response surface methodology (Pham Tan et al., 2012).

The Response Surfaces Methodology (RMS) is a technique that objective is to quantitatively determine the variations of the response function with respect to significant influence factors.

The screening plans had only two levels of study per factor and the mathematical models used were of the first degree (with or without interactions) with respect to each factor. These plans lead sometimes to simple modeling (Tinsson, 2010). However, there are many cases where it is necessary to have a good modeling of the studied phenomena and where it is necessary to pass to mathematical models of the second degree. Response surface plans are then used.

These plans have been applied as a result of the screening study as they only use factors previously considered influential. The RSM uses second-degree polynomial models (Goupy, 2005).

\section{Experience matrix}

The composite design is made up of three elements:

- Factorial design: consisting of experience points located at the vertices of square (for two factors), as well as checkpoints in the center of the study domain.

- Design star: the choice of the location of the star point is related to the experimental conditions and theoretical considerations based on optimality criteria.

- Points in the center: these points are important and have many roles. They are used to test the model validity of the first degree, allow obtaining the experimental error estimation, decreasing the prediction error near the center point and they are involved in determining " $\alpha$ ".

The total tests number $\mathrm{n}$ performed in a composite design is:

$$
\mathrm{n}=\mathrm{nf}+\mathrm{n} \alpha+\mathrm{n} 0 \quad \text { eq. } 2
$$

With:

nf: number of factorial design trials; n $\alpha$ : number of tests of star design; n0: number of trials in the center.

The composite design with two factors has given us an experience matrix 12 trials. The study domain is replaced by the domain $(-1,+1)$ and the 12 tests described by the experiments matrix were performed (Table 2). 
Table 2: Matrix experiments.

\begin{tabular}{lcc}
\hline Test number & $\mathbf{X 1}$ & $\mathbf{X 2}$ \\
\hline 1 & -1.00 & -1.00 \\
2 & 1.00 & -1.00 \\
3 & -1.00 & 1.00 \\
4 & 1.00 & 1.00 \\
5 & 1.21 & 0.00 \\
6 & -1.21 & 0.00 \\
7 & 0.00 & 1.21 \\
8 & 0.00 & -1.21 \\
9 & 0.00 & 0.00 \\
10 & 0.00 & 0.00 \\
11 & 0.00 & 0.00 \\
12 & 0.00 & 0.00 \\
\hline
\end{tabular}

\section{Mathematical model and statistical analysis}

The mathematical model postulated and used for composite designs is a model of the second degree in which the constant coefficient is retained, the terms of the first degree, rectangles terms and the terms of the second degree. There are no interactions of order 3 or more (Goupy, 2005).

The steam distillation yield (Y) depends on these factors above. The resulting mathematical model is a polynomial of order 2 as:

$\mathrm{Y}=\mathrm{b} 0+\mathrm{b} 1 \mathrm{X} 1+\mathrm{b} 2 \mathrm{X} 2+\mathrm{b} 12 \mathrm{X} 1 \mathrm{X} 2+\mathrm{b} 11 \mathrm{X} 12+\mathrm{b} 22 \mathrm{X} 22+\varepsilon$

With:

Y: yield on essential oil (response); f: response functions; (X1, $\mathrm{X} 2)$ : the factors taken into account; bi (b0, b1, b2, b12, b11, b22): the factor coefficients; $\varepsilon$ : the error term.

This study was conducted using Nemrodw software (Mathieu et al., 2000). Mathematical models obtained were validated by the test of analysis of variance (ANOVA) and the model coefficients were considered significant for values of $p$ $<0.05$.

\section{RESULTS AND DISCUSSION}

\section{Experimental design}

The tests of the experimental design are performed and the results are recorded (Table 3 ). The results obtained by ANOVA mentioned in Table 4 indicate that the principal effect of model is significant since the probability of significance of p-value risk is inferior than 0.05 .

The analysis of variance allowed us to calculate the coefficient of determination $\mathrm{R}^{2}$ with its value is 0,998 . Thus, we can conclude that $\mathrm{R}^{2}$ quantifies a clear way the quality of the model used. This model supports the greater part of the explanation of the measured responses.
Table 3: Expérimental design.

\begin{tabular}{lccc}
\hline Test number & Time (min) & Ratio $(\mathbf{m l} / \mathbf{g})$ & Yield $(\%)$ \\
\hline 1 & 60.00 & 2.00 & 0.40 \\
2 & 180.00 & 2.00 & 0.51 \\
3 & 60.00 & 4.00 & 0.46 \\
4 & 180.00 & 4.00 & 0.58 \\
5 & 192.60 & 3.00 & 0.56 \\
6 & 47.40 & 3.00 & 0.42 \\
7 & 120.00 & 4.21 & 0.52 \\
8 & 120.00 & 1.79 & 0.45 \\
9 & 120.00 & 3.00 & 0.50 \\
10 & 120.00 & 3.00 & 0.50 \\
11 & 120.00 & 3.00 & 0.50 \\
12 & 120.00 & 3.00 & 0.51 \\
\hline
\end{tabular}

Table 5 shows the values of the model coefficients in which each coefficient is associated with its value, its standard error, t-student and its p-value. If the probability of significance $\mathrm{p}$-value corresponding to constant coefficient b0 is significant, it should be retained in the final model. If we set the acceptance probability coefficients to $\mathrm{p}$-value of 0.05 , we also retain the coefficients corresponding to the two studied factors: time of steam distillation (b1) and ratio (water/plant) (b2). As well as the coefficients of quadratic terms: b11 and b22. The effect of the interaction between time and steam distillation ratio (water/plant) was found not significant since the coefficient b12 has a p-value of 33.7 superior than 0.05 . The coefficient $\mathrm{b} 12$ can be eliminating from our model.

Residual variance measurement is derived to the analysis of variance and the experimental error measurement is carried out by the repetitions. We can therefore calculate the fit variance. The lack of fit value is smaller than the experimental error; it's reflecting the fitness of the model.

The model coefficients of the second degree shown in Table 5 allow us to define the quadratic model that summarizes the total of tests representing the extraction yield by hydro-distillation of Pistacia lentiscus essential oil:

$\mathrm{Y}=0.502+0.058 \mathrm{X} 1+0.031 \mathrm{X} 2-0.006 \mathrm{X}^{2}-0.010 \mathrm{X} 2^{2}$ eq. 4

\section{Graphical study}

The graphs below were developed by the software thanks to the mathematical model obtained and which will allow us to make predictions in the field of study.

Figures 1.a and 1.b show the graphs of the curves isoresponse and three-dimensional response surface for the yield of EO of P. lentiscus. Both figures determine the contribution of distillation time and ratio (water/plant) on the yield obtained by EO. Thus, the variation of the studied factors had a very important contribution to variation of essential oil yield of Pistacia lentiscus which rose from $0.4 \%$ to $0.58 \%$. 
Table 4: Analysis of variance.

\begin{tabular}{lcccc}
\hline Source of variance & Sum of squares & Degrees of freedom & Mean squares & Ratio \\
\hline Regression & $3.0288010^{-2}$ & 5 & $6.0576010^{-3}$ & 265.2952 \\
Residual & $1.3700110^{-4}$ & 6 & $2.2833410^{-5}$ & \\
Total & $3.0425010^{-2}$ & 11 & & \\
Lack of fit & $6.5000010^{-5}$ & 3 & $2.0666910^{-5}$ & $0.0001^{* * * *}$ \\
Pure error & $7.5000010^{-5}$ & 3 & $2.5000010^{-5}$ & 0.561 \\
\hline
\end{tabular}

***: highly significant coefficient; **: Very significant coefficient; *: Significant coefficient

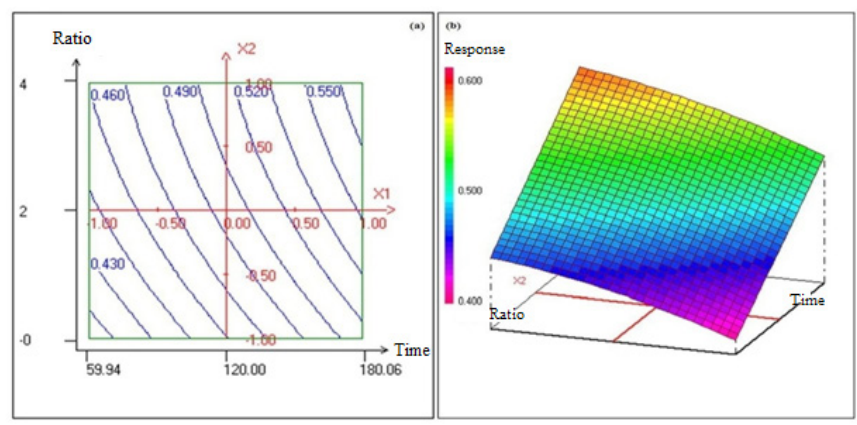

Fig. 1: Graph of isoresponse curves for essential oil yield of $P$. lentiscus (a). Graph of response surface for essential oil yield of $P$. lentiscus (b).

Table 5: Effect of model coefficients.

\begin{tabular}{lcccc}
\hline Name & Coefficient & $\begin{array}{c}\text { Standard } \\
\text { Error }\end{array}$ & t-student & $p$-value \\
\hline b0 & 0.502 & 0.002 & 214.89 & $<0.0001 * * *$ \\
b1 & 0.058 & 0.002 & 31.76 & $<0.0001^{* * *}$ \\
b2 & 0.031 & 0.002 & 17.07 & $<0.0001^{* * *}$ \\
b11 & -0.006 & 0.002 & -2.76 & $0.032^{*}$ \\
b22 & -0.010 & 0.002 & -4.24 & $0.005^{* *}$ \\
b12 & 0.002 & 0.002 & 1.05 & 0.337 \\
\hline
\end{tabular}

***: highly significant coefficient; **: Very significant coefficient; *: Significant coefficient

Both graphs show that we can have the desired yield in the domain of study for various operating conditions. Thus, a yield of $0.55 \%$ can be obtained using a ratio (water/plant) of value of 4 with a hydrodistillation time of $150(\mathrm{~min})$. The same yield can be obtained also with ratio of 2.9 and hydrodistillation time of 180 min. It would be wise to choose the most economically advantageous conditions.

To obtain a yield of $0.5 \%$ EO of $P$. lentiscus, the experimenter can reduce the extraction time from 165 to almost $95 \mathrm{~min}$, for a gain of $70 \mathrm{~min}$, with just a simple change in the ratio (water/plant) in the domain of study.

\section{Point test}

To confirm the results and finalize the validity tests of the proposed model, we verified with a test point. Thus, we conducted extraction test by steam distillation of EO of $P$. lentiscus.

The test point of the operating conditions and the experimental response and that predicted by the model are shown in table 6 .
Table 6: Predicted and experimental value for testing points.

\begin{tabular}{lcccc}
\hline Factor & $\begin{array}{c}\text { Encoded } \\
\text { value }\end{array}$ & $\begin{array}{c}\text { Real } \\
\text { value }\end{array}$ & $\begin{array}{c}\text { Predicted } \\
\text { response }\end{array}$ & $\begin{array}{c}\text { experimental } \\
\text { response }\end{array}$ \\
\hline Time of hydrodistillation & 0.5 & 150 & 0.544 & $0.550 \pm 0.002$ \\
Ratio (water/plant) & 0.5 & 3.5 & & \\
\hline
\end{tabular}

The obtained results indicate that there are no significant differences among the experimental responses. This confirms the prediction profile of postulated model.

\section{Chemical composition}

In order to simplify the analysis of the results, only compounds having abundance more than $0.5 \%$ were selected. Twenty nine compounds, which represented $78.71 \%$ of the total leaves essential oils, were identified. The results of chromatographic analysis of Pistacia lentiscus leaves essential oils are presented in Table 7.

\section{CONCLUSION}

The steam distillation is a path of recovery of aromatic and medicinal plant resources for the extraction of essential oils. Its effectiveness depends on both plant material and the extraction process implemented.

In this study, we were able to model and optimize the extraction of essential oil of Pistacia lentiscus by steam distillation thanks to experimental design, and more specifically to response surface methodology via a composite design.

This design associated with a mathematical model as polynomial of second degree, which was used to calculate the mean response, the effects of factors and interactions between these factors. Thus, the effect of the various studied parameters on the extraction process was evaluated. The essential oil yield according to the applied and validated mathematical model depends on the linear terms b1, b2 and quadratic terms b11, b22 corresponding 
to the time of steam distillation and the ratio (water/plant) respectively. Response surface methodology allowed to evaluate the effects of processing parameters and the extraction yields varied in the range of $0.4-0.58 \%(\mathrm{w} / \mathrm{w})$. It was a useful tool to investigate the optimal conditions for extraction of Pistacia lentiscus essential oil by steam distillation. For this plant, a time of steam distilation of $180 \mathrm{~min}$ and a ratio (water/plant) of 4 present the optimum operating conditions to maximize efficiency in EO. But it will always be wise to choose the most economically advantageous terms based on the isoreponse profile obtained and the response surface.

Table 7: Main constituents (\%) of Pistacia lentiscus leaves essential oil.

\begin{tabular}{|c|c|c|}
\hline $\operatorname{RI}(\min )^{a}$ & Compound $^{\mathrm{b}}$ & Area \% \\
\hline 915 & Tricyclene & 7.71 \\
\hline 953 & Camphene & 1.65 \\
\hline 974 & Sabinene & 6.96 \\
\hline 1006 & $\alpha$-Phellandrene & 2.61 \\
\hline 1011 & 3-carene & 4.44 \\
\hline 1026 & p-Cymene & 5.04 \\
\hline 1050 & trans- $\beta$-Ocimene & 3.89 \\
\hline 1072 & $\gamma$-Terpinene & 0.63 \\
\hline 1089 & p-Cymenene & 0.59 \\
\hline 1180 & Terpinen-4-ol & 7.44 \\
\hline 1192 & $\alpha$-Terpineol & 4.16 \\
\hline 1219 & Trans-Carveol & 0.62 \\
\hline 1266 & Geraniol & 0.58 \\
\hline 1288 & Bornyl acetate & 3.32 \\
\hline 1294 & Undecanone & 0.80 \\
\hline 1348 & $\alpha$-Cubebene & 1.06 \\
\hline 1381 & $\alpha$-Copaene & 0.83 \\
\hline 1395 & $\beta$-Elemen & 0.94 \\
\hline 1418 & Caryophyllene & 6.62 \\
\hline 1454 & $\alpha$-Caryophyllene & 1.65 \\
\hline 1462 & Benzoic acid, pentyl ester & 0.57 \\
\hline 1464 & Aromadendrene & 0.65 \\
\hline 1499 & $\alpha$-Muurolene & 1.83 \\
\hline 1513 & $\gamma$-Cadinene & 0.68 \\
\hline 1523 & Calamenene & 0.80 \\
\hline 1528 & $\delta$-Cadinene & 1.97 \\
\hline 1538 & $\alpha$-Cadinene & 1.90 \\
\hline 1581 & Caryophyllene oxide & 6.05 \\
\hline 1652 & $\alpha$-Cadinol & 2.72 \\
\hline
\end{tabular}

a: retention indices on HP-5 capillary column.

b: Compounds present in trace amounts $(<0.5 \%)$ were not registered.

These results can be a basis for the extrapolation of experimental conditions optimization of EO mastic extraction by pilot or industrial process. So they can have a great economic interest, especially after the confirmation of the time's effect of steam distillation and the ratio (water/plant) on maximizing yields.

\section{REFERENCES}

Bachrouch O, Ben Jemâa JM, Aidi WW, Thierry T, Brahim M. and Manef, A. Composition and insecticidal activity of essential oil from Pistacia lentiscus L. against Ectomyelois ceratoniae Zeller and
Ephestia kuehniella Zeller (Lepidoptera: Pyralidae). Journal of Stored Products Research, 2010; 46: 242-247.

Bayer E, Buttler KP, Finkenzeller X, Grau J. 2009. Guide de la flore méditerranéenne : Caractéristiques, habitats, distribution et particularités de 536 espèces. Edition Delachaux et Niestlé, Paris. pp. 94.

Benhammou N, Bekkara AF, Panovska KT. Antioxidant and antimicrobial activities of the Pistacia lentiscus and Pistacia atlantica extracts. African Journal of Pharmacy and Pharmacology, 2008; 2: 2228.

Clevenger JF. Apparatus for the determination of volatile oil. Journal of the American Pharmacists Association, 1928; 17: 341-346.

Daferera D, Pappas C, Tarantilis PA, Polisiou M. Quantitative analysis of pinène and myrcène in mastic gum oil using FT-Raman spectroscopy. Food Chemistry, 2002; 77: 511-515.

Djenane D, Yangüela J, Montañés L, Djerbal M, Roncalés P. Antimicrobial activity of Pistacia lentiscus and Satureja montana essential oils against Listeria monocytogenes CECT 935 using laboratory media: Efficacy and synergistic potential in minced beef. Food Control, 2011; 22: 1046-1053.

Duru ME, Cakir A, Kordali S, Zengin H, Harmandar M, Izumi S, Hirata T. Chemical composition and antifungal properties of essential oils of three Pistacia species. Fitoterapia, 2003; 74: 170-176.

Fadil M, Farah A, Ihssane B, Lebrazi S, Chraibi M, Haloui T, Rachiq S. The screening of parameters influencing the hydrodistillation of Moroccan Mentha piperita L. leaves by experimental design methodology. J. Mater. Environ. Sci., 2016 ; 7 (4): 1445-1453.

Goupy J. 2005. Pratiquer les plans d'expériences. DUNOD, Paris. 2016; 295-444.

Haj Ammar A, Fethi Z, Mehrez R. Optimization of operating conditions of Tunisian myrtle (Myrtus communis L.) essential oil extraction by a hydrodistillation process using a 24 complete factorial design. Flavour and Fragrance journal, 2010; 25, 503-507.

Haloui T, Farah A, Balouiri M, Chraibi M, Fadil M, Benbrahim FK, Alaoui BA. Bacteriostatic and Bactericidal Profile of Leaves and Twigs Essential oils of Moroccan Pistacia lentiscus L. Journal of Applied Pharmaceutical Science, 2015; 5 (6): 50-53.

Haloui T, Farah A, Lebrazi S, Fadil M, Alaoui BA. Effect of harvesting period and drying time on the essential oil yield of Pistacia lentiscus L. leaves. Der Pharma Chemica, 2015; 7(10): 320-324.

Haloui T, Fadil M, Jennan S, Farah A, Alaoui BA. Application of Plackett Burman design in the essential oil extraction by hydro-distillation process of Pistacia lentiscus L. leaves. Journal of Materials and Environmental Science, 2015; 6 (4): 942-948.

Hmamouchi M. 2001. Les plantes médicinales et aromatiques marocaines : utilisations traditionnelles, marchés, biologies, écologies, chimie, pharmacologie, toxicologie, lexiques. 2éme édition. pp. 140.

Mathieu D, Nony J, Phan TL. NemrodW: New Efficient Methodology for Research using Optimal Design (NEMROD) Software, LPRAI, Marseille. 2000.

Pham Tan LQ, Thi Kieu XN, Thi kim NH, Thi Hong XN. Application of response surface methodology (RSM) in condition optimization for essential oil production from Citrus latifolia. Emir. J. Food Agric., 2012; 24 (1): 25-30.

Tinsson W. 2010. Plans d'expérience: constructions et analyses statistiques, Mathématiques et Applications. Springer-Verlag, Berlin Heidelberg: 1-114.

Zrira S, Benjilali B. Effect of drying leaf oil of Moroccan E. camaldulensis. Journal of Essen-tial Oil Research, 1991; 3: 443-444.

How to cite this article:

Haloui T, Farah A, Lebrazi S, Fadil M, Alaoui AB. Application of response surface methodology for the optimization of hydro-distillation extraction of Pistacia lentiscus L. essential oil. J App Pharm Sci, 2018; 8 (01): 050-054. 